Khalife, S., Mneymneh, B.E., Tawbe, A., Chatila, M.H., and Hamzeh, F. (2018). "Employing Simulation to Study the Role of Design Structure Matrix in Reducing Waste in Design." In: Proc. $26^{\text {th }}$ Annual Conference of the International. Group for Lean Construction (IGLC), González, V.A. (ed.), Chennai, India, pp. 879889. DOI: doi.org/10.24928/2018/0249. Available at: www.iglc.net.

\title{
EMPLOYING SIMULATION TO STUDY THE ROLE OF DESIGN STRUCTURE MATRIX IN REDUCING WASTE IN DESIGN
}

\author{
Salam Khalife ${ }^{1}$, Bahaa Eddine Mneymneh ${ }^{2}$, Amena Tawbe ${ }^{3}$, \\ Mohamad Hilal Chatila ${ }^{4}$, and Farook Hamzeh ${ }^{5}$
}

\begin{abstract}
The design process is a complex and dynamic system owing to the interdependencies of tasks which need to be coordinated between different involved parties. As the design process continues to grow in complexity with the progress of design, and since the early stages are the most complex to manage, this paper proposes the use of the design structure matrix (DSM) to overcome the encountered challenges within the design management process. This study is based on the implementation of the DSM method to manage information flow in the preliminary design of a building project following a traditional design approach. Based on interviews with multidiscipline practitioners, tasks are identified and presented in a Base DSM. To better manage dependencies and improve performance, tasks are re-sequenced in a Partitioned DSM. Accordingly, two simulation models were developed for the Base DSM and the Partitioned DSM. Results show that the flow of tasks in traditional design leads to an increase in the design duration due to negative iterations representing rework in tasks receiving modified input from subsequent activities. Results also show the cyclic dependency between considered tasks and the effect of information change on work progress. This paper concludes by suggesting the application of an integrated design approach to manage the current planning system of the design process at early stages, where intensive coordination is required.
\end{abstract}

\section{KEYWORDS}

Design Structure Matrix, integrated design, work flow, waste, work structuring.

1 PhD student, Civil and Envir. Eng. Dept., American Univ. of Beirut, Beirut, Riad El-Solh 1107 2020, Lebanon,sgk19@mail.aub.edu

2 PhD student, Civil and Envir. Eng. Dept., American Univ. of Beirut, Beirut, Riad El-Solh 11072020 , Lebanon, bom02@mail.aub.edu

3 Graduate student, Dept. of Industrial Eng. And Mngmnt., American Univ. of Beirut, Beirut, Riad ElSolh 1107 2020, Lebanon, ait04@ mail.aub.edu

4 Student, Civil and Envir. Engrg. Dept., American Univ. of Beirut, Beirut, Riad El-Solh 11072020 , Lebanon, mac28@mail.aub.edu

5 Assistant Professor, Civil and Envir. Eng. Dept., American Univ. of Beirut, Beirut, Riad El-Solh 1107 2020, Lebanon,+961 1350000 Ext 3616, fh35@aub.edu.lb 
Salam Khalife, Bahaa Eddine Mneymneh, Amena Tawbe,

Mohamad Hilal Chatila and Farook Hamzeh

\section{INTRODUCTION}

The design process is a highly complex phase in the project life cycle due to the iterative and generative nature of design (Ballard 2000). Design iterations are of two types, positive iteration (value adding) and negative iteration (non-value adding) (Ballard 2000).Negative iterations are considered as waste and need to be mitigated.Complexity in design is also due to the fact that many design decisions are made independently making the management of work flow between different involved parties highly difficult and expressly important (Ballard \& Koskela 1998). This complexity is further accentuated by the interdependencies present between different disciplines within the same organization. Parraguez et al. (2016) categorized the interdependencies in the design process into three domains: the process domain (network of activities), the organization domain (a network of people), and the product domain (a network of components). These interdependencies disrupt the flow of information leading to design errors and time loss. To elaborate more on the process domain, Tuholski and Tommelein (2010) classified three types of activity dependencies: independent/parallel, dependent/sequential, and interdependent/coupled.

Several methods have been used to optimize the design process, improve work flow and reduce waste. The Last Planner System (LPS) was implemented to improve the design processes through managing its variability and improving reliability (Hamzeh et al. 2009; Wesz et al. 2013; Fosse \& Ballard 2016). Other methods such as the set-based design and the target value design has been recommended by lean practitioners to support lean design management and decrease negative iterations in design (Ballard 200).Ko and Chung (2014) developed a lean design process to establish an organizational learning environment which enhances timely feedback cycles hence reducing the likelihood of errors occurring. Additionally, the Social Network Analysis (SNA) has been employed in design to study the interdependencies of the design teams and visually understand the interaction and communication between parties (Al Hattab \& Hamzeh 2015). To analyse design workflow, Al Hattab and Hamzeh (2016) used an Angent Based Modelling (ABM) approach to study the workflow between design players by integrating both the social and process aspects. This helped in determining the impact of teams' structures on the status of design workflow.

Another tool was recommended by Ballard (2000) to reduce rework in design which is the Design Structure Matrix (DSM). The design structure matrix is a visual tool that represents the different levels of interactions within a system (Eppinger and Browning 2012). DSM is used to plan and improve the execution of complex projects through managing the interdependency between tasks, allowing for a smooth flow of information (Yassine 2004; Tuholski and Tommelein 2010). Browning (2016) reviewed 553 research papers on DSM across a wide range of industries. He concludes that DSM has a strong presence in engineering design and management, yet more work is needed to broaden its applicability. As such, researchers have been studying the effect of DSM in minimizing the complexity of design processes and improving workflow (e.g., Hammond et al. 2000; Yassine and Braha 2003; Hickethier et al. 2012).

However, although previous studies showed the beneficial aspects of using the mentioned tools to improve design, the current practice is still behind in implementing 
such tools. Our objective in this paper is to reflect on the current practices in traditional design. This paper introduces simulation to help in numerically realizing the need to enhance the design process and minimize the duration of the design phase by adopting efficient tools such as the design structure matrix. Additionally, we aim at showing the need for an integrated design process along with the necessary tools to improve the whole process. This research contributes to the body of knowledge in further proving the importance of better planning the early design phasesto work efficiently and reduce waste.

\section{METHODOLOGY}

In order to achieve the aforementioned objectives, the planning and control of the design process for a typical building project at its early stages is assessed. The study consists of four major stages: (1) Acquiring data through a survey with experts, (2) Setting up the Base DSM, (3) Creating the Partitioned DSM, and (4) Employing simulation and identifying improvements.

In the first step, following thorough consultations with practitioners fromvarious disciplines involved in the design phase, major tasks necessary for the completion of the preliminary design stage, and their dependencies, are identified. Then, these tasksare displayed on the Base DSM along with their dependencies. Following many iterations, the DSM was partitioned to identify the tasks' sequence that minimizes feedback loops, which should lead to an improvement in the flow of information and design decisions and will ultimately shorten the duration of the design process by reducing waste.

Finally, using simulation, the Base DSM and the Partitioned DSM are compared, in terms of the duration of the design process. Based on data from the survey, a Task-Based DSM simulation using "Any Logic" is executed to assess the project duration, mainly affected by negative iteration and rework, for the two design strategies. The rework risk factors are influenced by the probability of change in inputs of activities depending from each other and its effect on the project tasks' schedule (Yassine 2004).

Based on simulation results, a comparison between the current practices and the integrated approach is performed to determine the increase in the project duration due to negative iterations. The results helped understand the effect of the integrated approach on the improvement of the overall production process.

\section{BASE DSM: TASKS IDENTIFICATION AND DEPENDENCIES}

Interviews were conducted with practitioners from architecture, structure and MEP disciplines from different design consultancy firms in Lebanon. Practitioners were asked to identify the major tasks necessary for the submittal of a residential building project at the preliminary design stage. Respondents participated in the survey are shown in Table 1.

Table 1: Respondents

\begin{tabular}{c|c}
\hline Disciplines of Respondents & Number of Respondents \\
\hline Architecture & 16 \\
Structure & 16 \\
Mechanical & 12 \\
Electrical & 8 \\
\hline
\end{tabular}


Salam Khalife, Bahaa Eddine Mneymneh, Amena Tawbe,

Mohamad Hilal Chatila and Farook Hamzeh

Respondents include 16 architects, 16 structural, 12 mechanical and 8 electrical engineers involved in different types of residential, commercial and industrial projects with an experience range varying from 10 to 30 years in the design field.

First the interviewees were asked to decompose the project into a process that includes the major tasks performed during the preliminary design stage for a building project, each according to his/her own discipline. Based on the collected data, a Base DSM was developed and represented in Table 2.

Table 2: Base DSM

\begin{tabular}{|c|c|c|c|c|c|c|c|c|c|c|c|c|c|c|c|c|c|c|}
\hline \multicolumn{3}{|c|}{ Primary Design Tasks } & A1 & A2 & A3 & A4 & A5 & A6 & A7 & S1 & S2 & S3 & ME1 & M2 & M3 & M4 & E1 & E2 \\
\hline \multirow{7}{*}{ 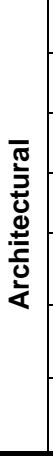 } & Plans & A1 & ) & & & & & & & 3.00 & & & 3.00 & & & & 1.90 & \\
\hline & Sections & A2 & 2.25 & & & & & 1.00 & & & 2.25 & & & 1.00 & & & & \\
\hline & Elevations & A3 & 2.25 & & & & & & & & & & & & & & & \\
\hline & Finishing & A4 & 1.50 & & & & & & & & & & & & & & & \\
\hline & $\begin{array}{c}\text { Doors \& Windows } \\
\text { Schedules }\end{array}$ & A5 & 2.25 & & 3.00 & & & & 1.75 & & & & & & & & & \\
\hline & $\begin{array}{c}\text { False Ceiling } \\
\text { layouts }\end{array}$ & A6 & 2.25 & 2.25 & & & & & & & 1.40 & & & 2.25 & & & & \\
\hline & $\begin{array}{l}\text { Fire Zoning } \\
\text { layouts }\end{array}$ & A7 & 2.75 & & & & & & & & & & & & & & 1.25 & \\
\hline \multirow{3}{*}{ 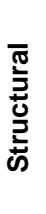 } & $\begin{array}{l}\text { Layout \& Sizing of } \\
\text { Vertical Elements }\end{array}$ & S1 & 3.00 & & & 2.25 & & & & & & & & & & & 2.00 & \\
\hline & $\begin{array}{c}\text { Layout \& Sizing of } \\
\text { Slabs/Beams }\end{array}$ & S2 & 3.00 & & & 2.10 & & & & & & & & & 1.20 & & & \\
\hline & $\begin{array}{l}\text { Location \& Sizing } \\
\text { of Footings }\end{array}$ & S3 & & & & & & & & 3.00 & 3.00 & & & & & & & \\
\hline \multirow{4}{*}{$\begin{array}{l}\overline{\mathbb{J}} \\
\frac{.}{\bar{N}} \\
\frac{c}{d} \\
\Sigma \\
\Sigma\end{array}$} & MEP Shafts & ME1 & 3.00 & & & & & & & & & & & 14 & 1.00 & & & \\
\hline & $\begin{array}{c}\text { Routing \& Sizing } \\
\text { HVAC }\end{array}$ & M2 & 3.00 & 1.40 & & & & & & & 3.00 & & & & & & & \\
\hline & Plumbing & M3 & 3.00 & 1.10 & 1.00 & & & & & & & & 2.00 & & & & & \\
\hline & $\begin{array}{c}\text { List of Power } \\
\text { Req. to Electrical }\end{array}$ & M4 & & & & & & & & & & & & 2.50 & 1.30 & & & \\
\hline \multirow{2}{*}{ 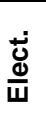 } & $\begin{array}{l}\text { Transformer } \\
\text { Rooms }\end{array}$ & E1 & 2.75 & 1.20 & & & & & 1.45 & & & & & & & 1.75 & & \\
\hline & Earth Pits location & E2 & 2.50 & & & & & & & & & 2.00 & & & & & & \\
\hline
\end{tabular}

The Base DSM shows the traditional arrangement of tasks with respect to each discipline working independently from the other. Given these points, practitioners had also to identify the required inputs and outputs for each activity in order to determine the dependencies between these tasks and to validate their cyclic dependent nature. In addition, Table 2 displays the value of the dependencies degrees of importance between different selected tasks. These values were calculated by finding the average frequency of dependencies between tasks. Three dependency values were adopted and classified in terms of importance as follows: (a) low (L) for values ranging between 1.00 and 1.50 (yellow cells), which mean that the corresponding tasks are low dependent from each other and their relation doesn't not seriously interrupt the flow of information, (b) 
medium (M) for values 1.50-2.00 (orange cells) representing tasks that are fairly dependent from each other and require reasonable coordination between participants, and (c) high $(\mathrm{H})$ for values 2.00-3.00(red cells)indicating that the corresponding tasks are highly dependent from each other, require intensive coordination between participants, and should be treated as high priority during the design process in order to proceed forward and avoid any potential rework.

For example, activity A1 needs input from activities S1 and ME1 with high dependency and from activity E1 with medium dependency, which means that activity A1 cannot be fully completed without having S1, ME1 and E1 finished first. An empty cell means no substantial dependencies are found between corresponding tasks. The practitioners justified the low dependencies between different tasks as based on incorporating assumptions in design, acquired from what they have learned from experience. These assumptions are resolved during the work progress and the low dependent tasks are reviewed if needed.

To understand further the dependencies between the activities and the necessary outputs and inputs established in the Base DSM, a Spaghetti Graph (Yassine and Braha 2003) was developed (Figure 1).

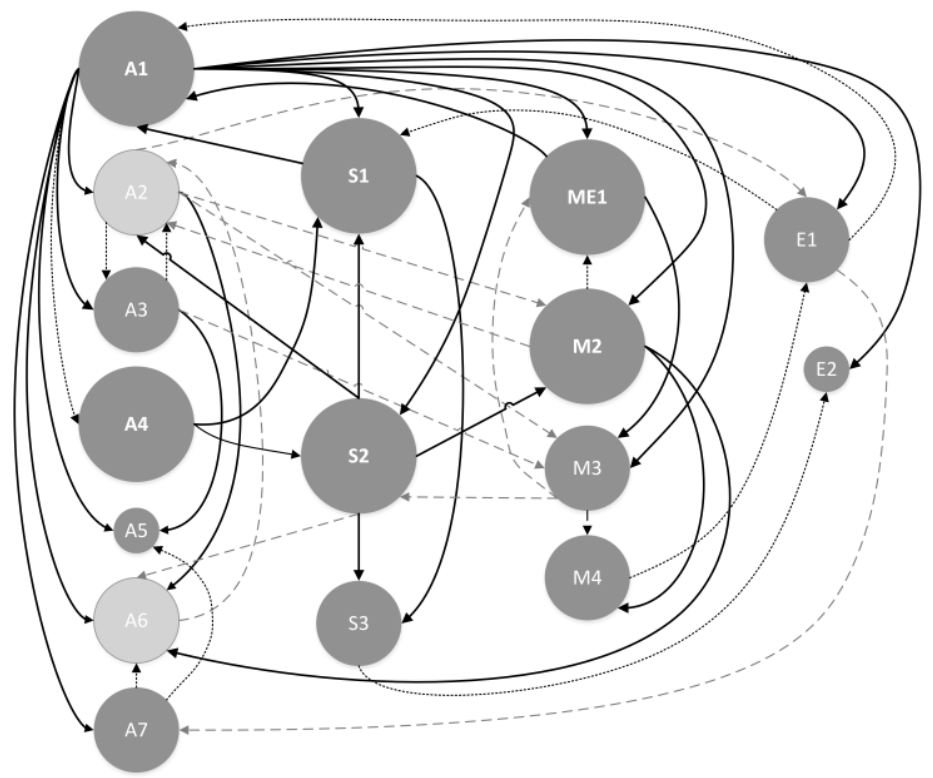

Figure 1: Spaghetti diagram

The different activities are represented as nodes. Arrows connected between nodes show the inputs and outputs for each activity. Arrows are represented according to the importance of dependency: High- continuous line, Medium- dotted line, Low- dashed line.

\section{PARTITIONEDDSM: REMOVING/ REDUCING FEEDBACK}

The Base DSM shows activities positioned in the adopted order of performing those activities within each discipline (Table 1). If a time sequence is associated with those activities, then all marks above the diagonal represent feedback loops (Yassine\&Braha 
Salam Khalife, Bahaa Eddine Mneymneh, Amena Tawbe,

Mohamad Hilal Chatila and Farook Hamzeh

2003). This indicates that these tasks are performed with incomplete information where the required inputs are not available at the needed time. Therefore, assumptions are made to complete the activity in the feedback loop. Those assumptions would be revisited as the project progresses and the needed input is available. This would lead to rework if the assumptions made were inaccurate which is considered waste in the time consumed on executing such activity and other dependent activities.

As a result, the matrix needs to be reorganized to remove or reduce feedbacks. This is done through analyzing the medium and high dependencies found above the diagonal which have a high probability in causing rework of other activities. This is known as the partitioning process (Yassine \& Braha 2003). After several re-shuffling of activities, the final Partitioned DSM is represented in Table 3.

Table 3: Partitioned DSM

\begin{tabular}{|c|c|c|c|c|c|c|c|c|c|c|c|c|c|c|c|c|c|}
\hline \multicolumn{2}{|c|}{ Preliminary Design Tasks } & A1 & A4 & S2 & S1 & ME1 & M2 & M4 & E1 & A2 & A3 & M3 & A7 & A6 & S3 & E2 & A5 \\
\hline Plans & A1 & & & & $\mathrm{H}$ & $\mathrm{H}$ & & & M & & & & & & & & \\
\hline Finishing & A4 & $\mathrm{M}$ & & & & & & & & & & & & & & & \\
\hline $\begin{array}{l}\text { Layout \& Sizing of } \\
\text { Slabs/Beams }\end{array}$ & S2 & $\mathrm{H}$ & $\mathrm{H}$ & & & & & & & & & & & ว. & & & \\
\hline $\begin{array}{l}\text { Layout \& Sizing of } \\
\text { Vertical Elements }\end{array}$ & S1 & $\mathrm{H}$ & $\mathrm{H}$ & $\mathrm{H}$ & & & & & M & & & & & ouple & d lo & & \\
\hline MEP Shafts & ME1 & $\mathrm{H}$ & & & & & M & & & & & & & & & & \\
\hline Routing \& Sizing HVAC & M2 & $\mathrm{H}$ & & $\mathrm{H}$ & & & & & & & & & & & & & \\
\hline $\begin{array}{c}\text { List of Power Req. to } \\
\text { Electrical }\end{array}$ & M4 & & & & & & $\mathrm{H}$ & & & & & & & & & & \\
\hline Transformer Rooms & E1 & $\mathrm{H}$ & & & & & & M & & & & & & & & & \\
\hline Sections & A2 & $\mathrm{H}$ & & $\mathrm{H}$ & & & & & & & & & & & & & \\
\hline Elevations & A3 & $\mathrm{H}$ & & & & & & & & M & & & & & & & \\
\hline Plumbing & M3 & $\mathrm{H}$ & & & & $\mathrm{H}$ & & & & & & & & & & & \\
\hline Fire Zoning layouts & A7 & $\mathrm{H}$ & & & & & & & & & & & & & & & \\
\hline False Ceiling layouts & A6 & $\mathrm{H}$ & & & & & $\mathrm{H}$ & & & $\mathrm{H}$ & & & M & & & & \\
\hline $\begin{array}{l}\text { Location \& Sizing of } \\
\text { Footings }\end{array}$ & S3 & & & $\mathrm{H}$ & $\mathrm{H}$ & & & & & & & & & & & & \\
\hline Earth Pits location & E2 & $\mathrm{H}$ & & & & & & & & & & & & & M & & \\
\hline $\begin{array}{l}\text { Doors \& Windows } \\
\text { Schedules }\end{array}$ & A5 & $\mathrm{H}$ & & & & & & & & & $\mathrm{H}$ & & M & & & & \\
\hline
\end{tabular}

\section{DISCUSSION}

The Partitioned DSM helped in identifying the sequential, parallel, and coupled tasks. Note that the Partitioned DSM may not show the optimal sequence of tasks, but it aids the process in reducing iterations. The iterative loop(Table 3) is more confined compared to the disarranged loop covering the whole Base DSM (Table 2). Amajor coupled loop was 
found which includes 8 activities (A1, A4, S2, S1, ME1, M2, M4 and E1). Those activities are related to all four disciplines which indicate the need of upfront coordination across functional teams at the beginning of the design process. The loop which includes tasks with high dependencies represents a cluster where design integration between people in charge is needed. This will help in executing the necessary tasks while completing the activities with minimal time and least rework. Relating it to the Spaghetti Graph, six of the eight activities included in the loop were represented as big nodes indicating high interdependencies.

The A1 activity (plans), having highest number of outputs required for the completion of other activities (13 outputs), needs input from 3 activities (S1, ME1, \& E1) from the structural, mechanical, and electrical disciplines. In return those 3 activities are also dependent on other activities; therefore, all shall be included in the same loop called the iterative loop. The iterative loop represents a loop of information flow that require people having input/output within this loop not to work independently. To that effect, empty cells represent tasks that can achieved following the traditional design approach, while filled cells require the need for collaboration between the relative involved parties. Another coupled loop includes A2 and A3 activities (sections \& elevations) is found where several iterations are required between these two activities during the design process.

Therefore, what was remarkably observed while interviewing the practitioners is that architects who were not using the latest industry's technologies were more concerned and keen to identify dependencies, while others who were using BIM, Revit as an example, were more hassle-free relying on such tool to facilitate dynamic and efficient coordination. Therefore, implementing a combination of DSM and BIM during the design can be useful in organizing design activities and allowing for proper coordination.

Moreover, coupled loops may seem confusing for design teams since they cannot work independently. On the other hand, coupled loops help create value through aiding integrated teams spur innovation. Set-based design can implemented in the coupled loops where coordination and collaboration between the involved parties, within the coupled loop, facilitate building consensus for the considered alternatives. This approach consists of keeping alive multiple alternatives until the last responsible moment in order to come up with a better design decision, rather than rushing into choosing one alternative. This thus reduce rework and time wasted on distant back and forth information exchange.

The preliminary design stage involves critical decisions taken during the design process. In addition, cost for changes is the lowest in the early stages of design but builds up fast as the design progresses as per the Macleamy curves (Macleamy 2004). Failure to achieve a high level of collaboration leads to waste in both time and resources. Such waste is mainly due to the rise of design errors and the corresponding relevant rework, all affecting the quality of deliverables and clients value.

\section{SIMULATION RESULTS}

The simulation is based on the preliminary design process of a ten-story residential building project using "AnyLogic". The original durations of each activity are based on 
the initial estimate of design practitioners and are summarized in table 3. Accordingly, the total required duration, or value adding duration, is equal to 51 days. Two simulation models are created to assess the actual required duration of the design process, based on the sequences in the original and Partitioned DSM.

Table 4: Durations (days) of the design activities

\begin{tabular}{cccccccc}
\hline Task ID & Duration & Task ID & Duration & Task ID & Duration & Task ID & Duration \\
\hline A1 & 12 & A5 & 2 & S2 & 5 & M3 & 2 \\
A2 & 5 & A6 & 2 & S3 & 2 & M4 & 1 \\
A3 & 4 & A7 & 1 & ME1 & 3 & E1 & 2 \\
A4 & 3 & S1 & 4 & M2 & 2 & E2 & 1 \\
\hline
\end{tabular}

The simulation models are based on the assumption that a task requiring input from a preceding activity is completed based on assumptions made by the designer. If the assumption proves to be inaccurate, the task would have to be rechecked. Thus, rework occurs in tasks receiving modified input from subsequent activities. For example, activity (A1) depends on activity (S1) but is completed before it. If a change occurs in (S1), some rework for (A1) is required. In the simulation models, and according to practitioners, changes resulting from a strong dependency will induce a rework equal to $20 \%$ of the original duration of the activity, while changes resulting from a medium dependency will induce a $10 \%$ rework. As for the probability that a change occurs, this value is high for the first design iteration (80\%), and low (20\%) for the remaining iterations. In "AnyLogic", the simulation models are conducted as per the layouts presented in Figures 2 and 3. 


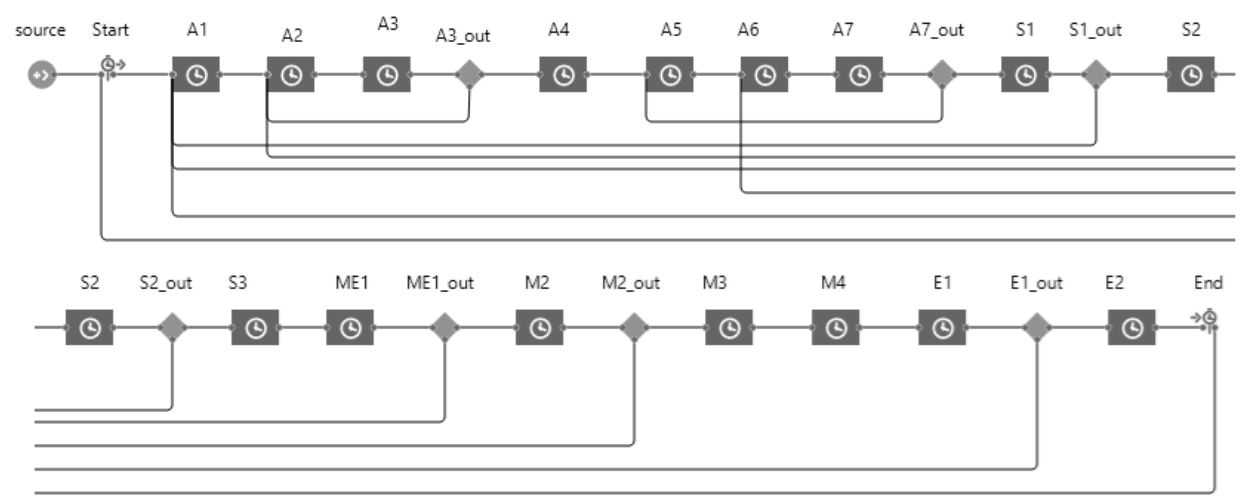

Figure 1: Simulation model for the Base DSM

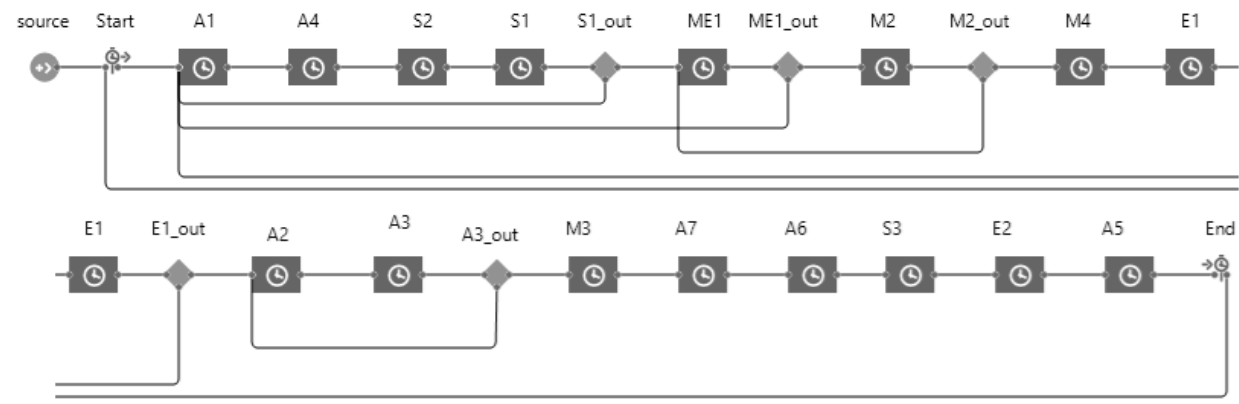

Figure 2: Simulation model for the Partitioned DSM

The interdependencies between activities are identical, while the tasks are sequenced according to the Base and Partitioned DSM. 23 variables are used to allow for the modelling of the possible changes in the durations of activities, and the probabilities of rework. For example, the duration of each activity (A1) (Figures 2 and 3) is equal to its original duration (12 days) multiplied by the variable representing the amount of required work for this activity (V_A1) which is originally set to 1 . When rework is required for activity (A1), changing the value of (V_A1) allows for the determination of the actual duration of this rework. "TimeMeasureStart" and "TimeMeasureEnd" blocks are utilized to calculate the total duration of the design process.

The effect of the Partitioned DSM on the reduction of the number of feedback loops is clear in the two models. It is important to note that the simulation model is a representation of the actual amount of work required, rather than the actual duration of the design process, since some activities may overlap. However, the interest of this study is to identify waste and negative iteration in design, which are based on the actual amount of work, not the total duration of the design phase.

Based on results from 1000 runs of the two models, the average number of workdays of the preliminary design phase was equal to 93 days for the Base DSM, and 66.4 days for the Partitioned DSM (Figure 4), compared with duration of the value adding activities, equal to 51 days. 


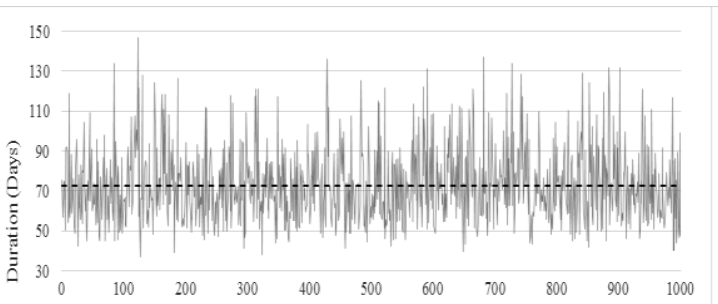

Base DSM simulation nun

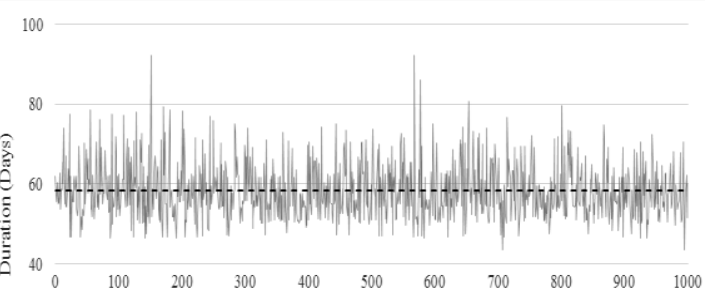

Partitioned DSM Simulation nun

Figure3: Duration of the design phase in Base DSM vs Partitioned DSM

However, even in the model of the Partitioned DSM, a high degree of variation in the calculated duration between runs exists. This is mainly due to the iterative nature of the design process. The minimum possible duration output, equal to 51 days, occurred only once in the 1000 runs, whereas the highest calculated duration was equal to 101.1 days.

\section{CONCLUSION}

The findings of this study show that design tasks in the traditional practices are executed based on sequential pattern of dependencies ignoring the iterative nature of the design process. The study reveals the importance of planning design tasks based on the design structure matrix DSM to minimize loops and reduce negative iterations which usually cause waste in design. The main idea of this study is to depart from the practitioners' traditional practices of executing tasks without involving downstream players and to promote a restructured design management process allowing for more coordination. The simulation results highlighted a $45.2 \%$ of waste in the design phase due to rework in tasks receiving modified input from subsequent activities. This percentage can be decreased to $23.2 \%$ by adopting an improved sequencing using the DSM. However, waste in design may still occur. This creates a sense of urgency to adopt an integrated design process due to the intensive exchange level of information during the early phases of the design process. Future research will aim to develop an implementation plan and assess its effect on shortening the duration and reducing the cost of the whole project.

\section{REFERENCES}

Al Hattab, M., and Hamzeh, F. (2015)."Using Social Network Theory and Simulation to Compare Traditional versus BIM-Lean Practice for Design Error Management." Automation in Construction, Elsevier, 59-69.

Al Hattab, M., and Hamzeh, F. (2016). "Analyzing design workflow: An agent-based modeling approach." Procedia Engineering, 164, 510-517.

Ballard, G. (2000). "Positive vs Negative Iteration in Design." $8^{\text {th }}$ Ann. Conf. IGLC, Brighton, $U K, 17-19$.

Ballard, G. and Koskela, L. (1998). "On the Agenda of Design Management Research.”6th Ann. Conf. IGLC, Guarujá, Brazil, 13-15.

Browning, T.R. (2016). "Design Structure Matrix Extensions and Innovations: A Survey and New Opportunities."IEEE Transactions on Eng.Management, 63(1), 27-52. 
Eppinger, S.D., and Browning, T.R. (2012). Design Structure Matrix Methods and Applications. MIT Press, Cambridge.

Fosse, R., and Ballard, G. (2016). "Lean Design Management in practice with the Last Planner System."24th Ann. Conf. IGLC, Boston, USA, 4, 33-42.

Hammond, J., Choo, H.J., Austin, S., Tommelein, I.D. and Ballard, G. (2000) "Integrating Design Planning, Scheduling, and Control With DePlan." ${ }^{\text {th }}$ Ann. Conf. IGLC, Brigthon, UK, 17-19.

Hamzeh, F.R., Ballard, G., and Tommelein, I. D. (2009). "Is the last planner system applicable to design? A case study. " $17^{\text {th }}$ Ann.Conf. IGLC, Taipei, Taiwan, 165-176.

Hickethier, G., Tommelein, I. D., and Gehbauer, F. (2012). "Reducing rework in design by comparing structural complexity using a multi domain matrix." $20^{\text {th }} \mathrm{Ann}$. Conf. $I G L C$, San Diego, USA.

Ko, C. H., \& Chung, N. F. (2014). "Lean Design Process." Journal of Construction Engineering and Management, 140(6).

MacLeamy, P. (2004). "MacLeamy Curve: Collaboration, Integrated Information, and the Project Lifecycle in Building Design." Construction and Operation, WP-1202.

Parraguez, P., Eppinger, S. and Maier, A. (2016). "Characterizing Design Process Interfaces as Organization Networks."Insights for Eng. Systems Manage, 19, 158-173.

Tuholski, S.J., and Tommelein I.D. (2010). "Design Structure Matrix Implementation on Seismic Retrofit." Journal of Management in Engineering, 26(3), 144-152.

Wesz, J., Formoso, C., and Tzortzopoulos, P. (2013). "Design Process Planning and control: last planner system adaptation." $21^{\text {st } A n n . ~ C o n f . ~ I G L C, F o r t a l e z a, ~ B r a z i l, ~ 369-~}$ 378.

Yassine, A., and Braha, D. (2003). "Complex Concurrent Engineering and the Design Structure Matrix Method."Concurrent Engineering: Research and Applications, 11(3), 165-176.

Yassine, A. (2004). "An Introduction to Modeling and Analyzing Complex Product Development Processes Using the DesignStructure Matrix (DSM) Method."Quaderni di Management, 9, 72-88. 